\title{
The Cartesian Legacy : Dealing with the Medicalization Challenge
}

\author{
Lata Shenava ${ }^{1}$ \\ ${ }^{1}$ Independent Researcher, EI-Certified Therapist, Trainer and Life Coach \\ E-mail-Ishenava@yahoo.com
}

\begin{abstract}
The mental health of future adult populations can be impacted by substantially improving the mental health of children. Post-industrialisation, the Mechanistic worldview, guided by the Cartesian model (restricted to the mind-body dimensions) replaced the Organismic view of nature that celebrated the Nature-Human interdependence. Moving away from holistic and promotive approaches of traditional cultures, the current public health model rooted in rational thought was mainly focused on drug-based, clinical and therapeutic approaches.

Post-colonisation, India was transformed from a primarily agrarian society to an industrialised one where the family" $s$ primary function was to prepare the child for the industrial environment. Based on my clinical, research and life experience of 3 decades, the paper attempts to build a case for a movement that reclaims our knowledge systems to guide research and policy to create health models that are accessible, affordable, promotive and most importantly culturally-relevant.
\end{abstract}

Keywords: Child and Family Mental Health, Reclaiming our Knowledge Systems, Cartesian legacy.

\section{BACKGROUND}

Children are the fundamental resources for human, social and economic development. Children constitute $37 \%$ of the world population and with almost half the global population under the age of 25 they form an extremely important resource for health interventions. Childrearing contexts, particularly urban, due to changing value orientation and the consequent demanding lifestyles characterised by conspicuous consumerism, reduced support systems and increased nuclearisation of the family unit hold inherent mental health risks for children [1]. The increasing "vulnerability" that children face can be gauged from mental health problems that range from social problems like fragmented families, child abuse, media violence, substance abuse to emotional problems of lack of affiliation, lack of Social interest, insecurity and instability. The burden of suffering experienced by children and their families are indicated by the growing numbers of children whose emotional, behavioural and developmental needs are not met by society and its institutions, created explicitly to take care of them. Worldwide, childhood neuropsychiatric disorders are projected to rise by $50 \%$ proportionately by the year 2020 to become one of the five most common 
causes of childhood mortality, morbidity and disability [2]. The global burden of severe emotional disturbances in children was an approximate 15\% [3]. Despite lofty policymaking and agendas at health forums, child well-being not being a global agenda was revealed by the fact that over $90 \%$ of nations had no child mental health policy. The contemporary Western health enterprise imposed on the world post-colonisation is rooted in a population-based public health model, where the main concern is the health of a population in its entirety within the physical and psycho-social parameters. Focus of health endeavours thus was predominantly on diagnosis, treatment, and etiology, the epidemiologic surveillance of the health of the population at large, health promotion, disease prevention and access to and evaluation of services [4]. Subsequently, extremely significant issues like emotional development, a sense of purpose and social connectedness associated with the spiritual dimension of mental health were largely disregarded in planning and policy. (Children mean all persons under the ae of 18 - UN Convention on the Rights of the Child).

Post-colonisation, along with the territorial, economic, political and social conquest (Jones 2004), Western powers ensured the 'Mcdonaldisation of the world' [5] through the enforcement of AWOL2 on the colonised nations [6]. The dominant Mechanistic Worldview shaped the central concepts and guiding assumptions that underpinned the understanding of development globally. Rooted in the certainty of scientific knowledge, the Western bio-medical model, epitomised by Descartes" celebrated statement "cogito, ergo sum" - "I think, therefore I exist," drew its theories and techniques mainly from modern psychiatry and social science, both not only alien to most cultures in Asia but also limited to attaining psychological health and returning the individual to baseline functioning. In addition, linking happiness and well-being to wealth creation created lifestyles that were hazardous to societal well-being. The Indian Context The measure of a society's health is how well it takes care of the youngest and oldest generations. By this standard, we have failed collectively as stakeholders (parents, schools, communities, policy makers, practitioners and researchers) as a majority of our children's mental health needs are not addressed. Apart from the universal issues of consumeristic and pressurised lifestyles, the omnipresent media culture, the transition from leisure to the entertainment culture, in India, the problem is compounded by continuing with a health system that is not only inadequate, inflationary, inaccessible to large populations but is totally removed from its own cultural systems of knowledge. Post-colonisation, India was gradually and insidiously transformed from a primarily agrarian and collectivistic society to an industrialised and consumeristic society that led to the decline of the larger kinship unit and the emergence of the self-contained nuclear family. Striking increases in social and emotional problems have been attributed to the individual and society being overwhelmed by the strong forces of the new culture, that replaced native ways of thought, tradition, value systems and ideologies, cherished and effective in the past.

Childhood was seen as a distinct phase with its unique developmental requirements and families as primary-care providers and childrearing was the product of joint families. Multiple caretakers with strong family bonds was considered significant in the development of the individual. With materialism as its reigning value and productivity its major objective, urban families treated childhood as the preparatory phase to equip children with skills to facilitate industrial discipline in adulthood. Literacy, seen as the trajectory to wealth accumulation, was consequently geared to creating a highly motivated, achievement-oriented workforce by all social structures (families, the 
educational system and political structures) where grades took precedence over the pursuit of knowledge to gain wisdom and holistic excellence. Thus, in a matter of two centuries, as was Macaulay's (1835/1972) [7] war strategy, we have been transformed from a nation of craftsmen and traders to one of clerks, peons and corporate coolies, I may add. The result is seen in the statistic of the Security guard profession employing the 2 nd highest number of people in India.

Lord Macaulay's address to the British parliament (2nd February, 1835) "I have travelled across the length and breadth of India and I have not seen one person who is a beggar, who is a thief. Such wealth I have seen in this country, such high moral values, people of such calibre, that I do not think we would ever conquer this country, unless we break the very backbone of this nation, which is her spiritual and cultural heritage, and, therefore, I propose that we replace her old and ancient education system, her culture, for if the Indians think that all that is foreign and English is good and greater than their own, they will lose their self-esteem, their native culture and they will become what we want them, a truly dominated nation."

Shaped by Western individualistic and capitalistic ideologies, urban families replaced the established conceptions of children requiring guidance and nurture with new conceptions of child competence that Elkind [8] termed as the Super-kid phenomenon ( $A$ child pressured by parents and society in general to do too much too soon., seen in the increased overscheduling of children" $s$ activities that may not only be age-inappropriate, but uninteresting to the child). Sociologist Manas Roy [9] opined that the westernised generations have moved from 'Gandhian frugality' and belonged to a modern India symbolised by consumerism and pleasure-oriented lifestyles. Notably, the new colonisers (the $15-20 \%$ India Shining segment) are the new role models that the remaining 800 million population (both rural and urban) wants to emulate in attaining AWOL [1]. (800 million - That's the number of Indians who still remain poor and vulnerable in the new India'. N. K. Singh, Indian Express, Sunday, 30th Sept. 2007)

\section{CHALLENGES IN CHILD MENTAL HEALTH PROMOTION}

[1] Role of families, the primary care-giving unit of society - a neglected area

Efforts and advocacy is largely geared towards increasing mental healthcare workers rather than investing in families and communities. Physical and infrastructural issues have precedence over factors that compromised the family's ability to provide safe and caring environments for their children.

[2] Are the current mental health interventions the right methodology?

Despite striking increases globally in emotional, psycho-somatic and psychiatric disorders in children, investigation into the origin and maintenance of emotional disorders is neglected.

[3] Childrearing styles not based on the child's developmental requirements and parental needs.

Childhood is not conceptualised as distinct from adulthood with its unique developmental requirements, thus denying its significance in societal mental health.

[4] Neglect of our rich knowledge systems. 
Anthropological, historical and philosophical studies have established that Indian texts and practices are rich sources of psychological knowledge. Govindaswamy [10] claims many psychological doctrines and results of modern research have been anticipated and commented upon with great insight by the ancient sages of India" (pg. 31).

Despite abundant approval by Western researchers of the profundity and value of our knowledge systems, all contemporary discourse, shaped by the Marxist denigration of traditional India [11], which itself is a revamped idea of the Descartes-Kant-Hegelian legacy is put down or marginalised. The deliberate destruction of India's cultural, political, economic and social systems like with the other areas of the world, especially the Americas and Africa, can be read in Marx's words [11] 'England has to fulfil a double mission in India: one destructive, the other regenerating-the annihilation of the old Asiatic society, and the laying of the material foundation of Western society in Asia.'

[5] The pre-dominant focus of research, policy and practice on the 'dysfunctional minorities' rather than the 'functional majorities.'

Recognising that a majority of children are healthy and socially competent, very little effort is put into highlighting the vulnerabilities that this majority is exposed to. Current-day interventions are predominantly problem-oriented and deficitbased rather than promotive and strength-based. Treatment modalities largely operate from the psychiatric paradigm within the realm of allopathic medicine. Additionally, traditional healing systems that were effective for more than 10,000 years, were rejected by the colonisers as unscientific and primitive. Yet the same pagan knowledge systems were digested [12] and put forth as their discoveries leading to either the extermination or marginalisation of our cultural systems.

A major fallout of our increasingly challenging lifestyles is the increased medicalisation of problems and the immediate recourse to medical care (tests, medication, or psychiatric intervention). Children are increasingly being medicated for what was perceived as psychological problems, which in actuality could be linked to the current stressful lifestyles that children are compelled and families choose to lead. Godlee [13] attributes the collusion between medical science and the drug industry for the increased usage of over the counter and prescribed drugs. An example of its pervasive nature is seen in lifestyle diseases (hypertension, high cholesterol, behaviour problems, stress, chronic constipation, obesity) being redefined as bona fide diseases to encompass a greater percentage of the population.

Figure 1 : The process of problem-creation 


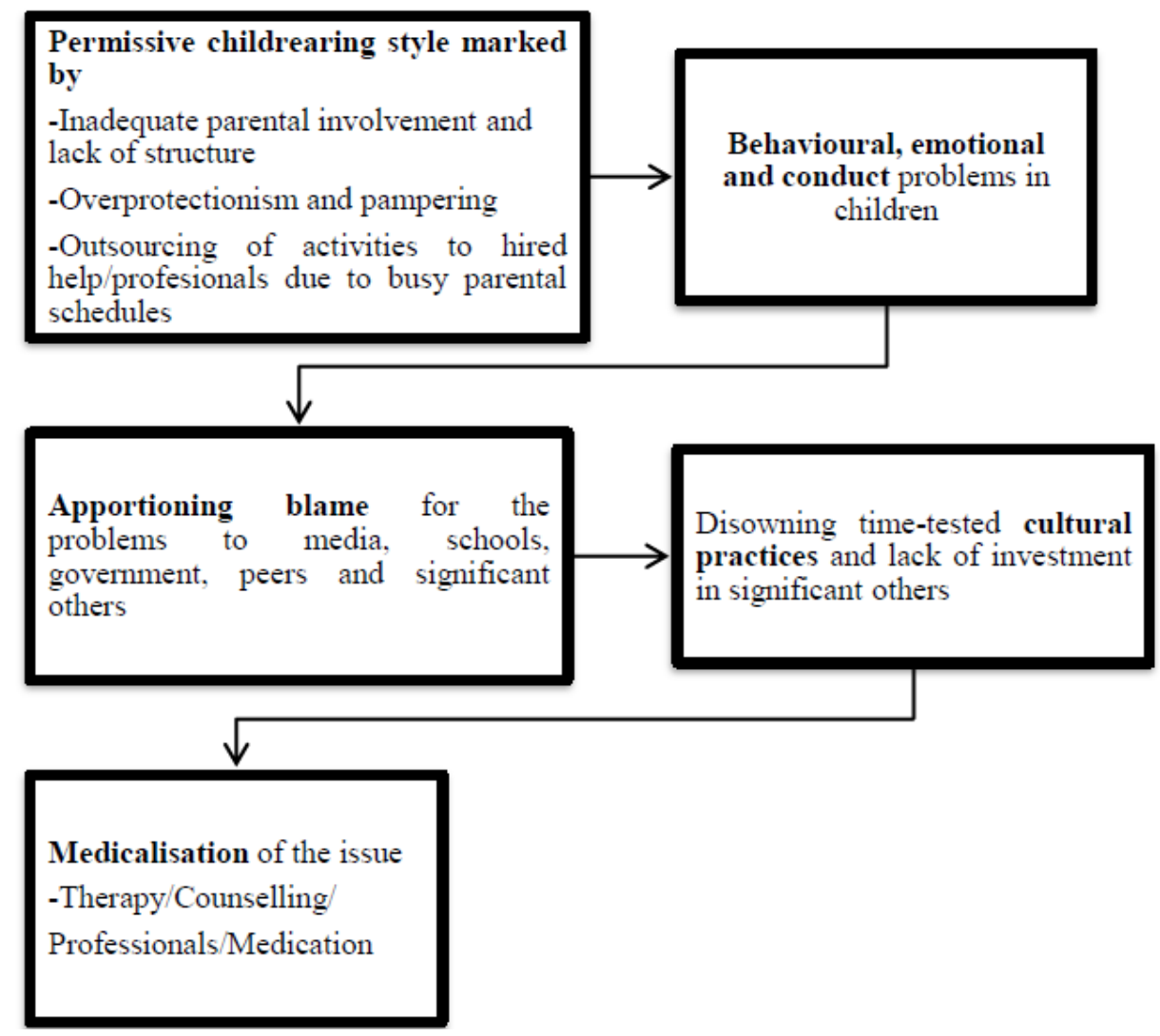

An example of this trend was seen in the daily routines of families and eating habits, where health problems were reported that were related to disorganised lifestyles. $78.7 \%$ of the families reported that bedtime is usually later than earlier times. Consequences to these poorly organised lifestyles included physical (obesity, lack of proactivity and selfeffort), emotional and conduct problems (hyperactivity, aggression, anxiety, poor selfesteem, etc.).

Notably, the new problem is not sleep deprivation, but sleep procrastination, where sleep is put-off deliberately to pursue other activities that revolve mainly digital entertainment and social networking. The consequences reported were lifestyle diseases, exhaustion and fatigue. However as a Life coach, I have seen more serious implications especially in the last decade in terms of a gradual but progressive decline in Critical enquiry, Resilience, Life and interpersonal relationship skills both in children and adults, especially in the building blocks of our nation, the youth.

\section{A BAZAAR OF SELF-HELP EXPERTS}

Dr. Allen Frances [14] cautions health professionals against using the DSM (The Diagnostic \& Statistical Manual) as a bible as he believes it could lead to "massive over-diagnosis and harmful over-medication. He is alarmed particularly by the latest DSM 5 as the American Psychiatric Association (APA) has despite pressure for an independent review, given final approval to ten "reckless and untested ideas. Where a differential diagnosis that explores the root cause of the problem would be prudent, the system itself promotes symptomatic and quick-fix approaches that have eventually resulted in increased drug-dependence and therapeutic approaches. He claims that 
newer disorders are being created, for example simple gluttony is now binge eating disorder or developmental cycle issues (normal forgetting of old age as a neuro-cognitive disorder at risk for dementia, normal grief as depression) where much cannot be done yet are made part of the treatment system. Of course, the at risk of being at risk to lifestyle disorders like diabetes, hypertension, etc. is now treated as a separate category complete with medication and therapy [13]. Affirming the dangerous side effects of the drugs, she advises management through less expensive strategies of lifestyle management, exercise, diet and discipline. Ironically, Indian health systems have always underscored these approaches [15].

A recent example of medicalising of common childrearing problems was the launching of a diagnostic tool, IMFeD (identification and management of feeding difficulties) by Abbott India, a pharmaceutical giant, for studying fussy children. Not only is this problem restricted to the affluent few (though the report mentions that $80 \%$ are affected by this problem), but also the causative factors (lack of play, increased media usage and decline in parental authority) are not discussed. Notably, the media abound in advertising about cutting-edge diagnosis and painless testing procedures to make your child's or husband's life happy (read comfortable) which indicates that the commercialisation of health as in education is here to stay.

The latest syndrome to the hit the West is the Youthful tendency disorder, a neurological condition afflicting an estimated 20 million U.S. children. YTD characterised by a variety of senseless, unproductive physical and mental exercises, lasting hours at a time and being in an unreal, unexplainable state of "make-believe". A YTD expert" (not my word, the journal article's word) believes them to be Unfit to join the adult world, they struggle to learn its mores and rules in a process that can take the entirety of their childhood

This is alarming for two reasons

1. The humungous number (20 million), which means they are not the dysfunctional minorities but definitely fall into the functioning majorities' category.

2. Routinely, if children's interactions are dominated by gadgets, the entertainment culture and service providers (school, tuitions, dance, robotics, speech and drama classes ferried across by drivers, maids and harried mothers) and there is drought of genuine face-to-face human (read peers, neighbours, extended family) engagement, then what is to be expected?

To quote Mitch Album from 'Tuesdays with Morrie', -We have become a bazaar of self-help experts, at 300 \$ an hour everything is available. In my clinical practice I am appalled to find that routine life problems that individuals dealt with some help from a 'favourite aunt/grandfather, a friendly neighbour or a caring parent/teacher' is directed to a health professional. The source of most of these problems could be traced to inadequate parent involvement, chaotic home environments and lack of responsibility in attending to the affiliation needs of the child. The preference for medical approaches that were quick-fix in nature also absolved the busy parent from working at the problem. Not undermining the important role that we professionals play in enhancing well-being of people, especially in modern societies where social supports are declining, the increased medicalisation and dependence on drug-based approaches is pushing more individuals into a mental health system that in itself is overburdened, inflationary, harmful and most importantly ineffective. Why ineffective? Because the current public health models are not working, neither the drugs nor the markets are working. In 
Mumbai, the BMC has initiated a committee to probe the TB deaths (IE July 17th, 2014) as the usual drugs are not working.

Western drug manufactures and governments are working on an overdrive to save them from the human-made disaster that Hirschler \& Kelland term Antibiotic apolcalyse (page 15, July 13 the Sunday Express), yet their solutions and hope lie in a business model (read Western) that rewards firms (read large multinationals) for developing new antibiotics. David Cameron, the British Prime Minister, has initiated a fund that finances research to discover new antibiotics within a time-bound programme. Yet in all these measures there is no effort directed to the root causes of pathology and emotional maladjustment or acknowledgement of the failure of the current health and economic model. The Way Forward In a matter of just 3 years, Francis Fukuyama [16], made a shift from his first premise that liberal democracies and free market capitalism is the most stable and equitable form of governance model to acknowledge that economics cannot work without Culture. The importance of social capital, institutions and capacity building in equitable economic development, something that was commonsense wisdom in our culture is now recognised by the West. A "shift in approach" is therefore mandatory in the addressal of child well-being issues in our country. Historically, socialisation forces within the various caregiving systems, especially in the family, nurtured the development of children. Finally, I quote Rajiv Malhotra, the true Indologist8 to emphasise the need to de-colonise the expanding strata of Westernised Indians and get away from being 'mental Europeans' a term used by Russell to describe what has become of the remaining $4 \%$ survivors of holocaust of natives by the new settlers in the Americas. - India is not a junior partner in a global capitalistic world, but has its own distinct and unified civilisation with a proven ability to manage profound differences, engage creatively with various cultures, religions and philosophies and peacefully integrate many diverse streams of humanity that stand in contrast to the fundamental assumptions of Western civilization. All stakeholders in child mental health need to work towards a "different" society that is guided by the heritage of its own culture, its beliefs, practices, and its worldviews and build a theoretical base specifically from the standpoint of child mental health and the all-important childrearing function. This then could be a starting point to create a promotive model of intervention that is accessible, affordable, culturally relevant and most importantly preventive.

\section{RECOMMENDATIONS}

I. Promotion of Societal Well-being (Mental health) should be a national agenda.

a. A separate Child \& Family health policy and a Parenting policy.

b. Macro-issues should be linked to Child mental health.

II. Parent training and education with focus on lifestyle management, personal growth and social development.

III. Research must explore child development through a socio-ecological approach in the following aspects:

a. Traditional childrearing practices.

b. Children's socio-emotional development.

c. Interpersonal relationships.

d. Resilience- risks, protective factors and strengths of families. 
Based on the unique interdependent self-concept and the Self-Ecology interplay of collectivistic cultures, Asian countries should collaborate to build a strong knowledge base that promotes a holistic, contextual and promotive health intervention plan.

\section{REFERENCES}

1. Shenava L. Doctoral Study. Childrearing and Child Mental Health: A Study of Non-Slum Families in Mumbai City. Mumbai, India: Tata Institute of Social Sciences ; 2011.

2. Nastasi B, Moore R, Varjasm K. School-Based Mental Health Services: Creating Comprehensive and Culturally Specific Programs. Washington, D.C.: American Psychological Association ; 2004.

3. World Health Organisation (WHO). Mental Health around the World, stop Exclusion - Dare to Care. Department of Mental Health and Substance Dependence. Geneva: WHO ; 2001.

4. Mental Health: Report of the Surgeon General. http://www.surgeongeneral.gov/library/mentalhealth. Retrieved on 3rd Dec. 2005.

5. Ritzer G. The Macdonaldization of Society. New Century Edition. California: Pine Forge Press ; 2000.

6. Alatas SH. The Myth of the Lazy Native: A study of the Image of the Malays, Filipinos and Javanese from the 16th to the 20th century and its Function in the Ideology of Colonial Capitalism. Routledge. UK: London ; 2010.

7. Louv R. Last Child in the Woods: Saving our Children from Nature-Deficit Disorder. N. Carolina: Algonquin Books of Chapel Hill ; 2005.

8. Elkind, D. The Hurried Child: Growing Up Too Fast Too Soon. USA: Addison-Wesley Publishing Company Inc ; 1988.

9. Dutta, D. Aging Parents- Home Alone. Cover Story. India Today. 16th July, 2007.

10. Murthy, S. The National Mental Health Programme: Progress and Problems. In Mental Health: An Indian Perspective, 1946-2003. New Delhi: Directorate General of Health Services, Ministry of Health and Family Welfare ; 2004.

11. Dharampal D. The Beautiful Tree: Indigenous Indian education in the Eighteenth Century. Collected Writings, Vol III. Mapusa: The Other India Press ; 2000.

12. Malhotra R. Being Different - An Indian Challenge to Western Universalism. India: Harper Collins ; 2011.

13. Godlee F. Are we at Risk of Being at Risk ? BMJ 2010;431:462.

14. Frances A. DSM 5 Is Guide Not Bible-Ignore Its Ten Worst Changes. http://www.psychologytoday.com/blog/dsm5-in-distress/201212/dsm-5-is-guide-notbible-ignore-its-ten-worst-changes. Retrieved on 25th July, 2013.

15. Shenava, L. Pre-doctoral Study. Child Mental Health: Emerging Themes. Mumbai, India: Tata Institute of Social Sciences ; 2008.

16. Fukuyama F. Trust: The Social Virtues and the Creation of Prosperity. New York: Free Press ; 1995.

Acknowledgements - Nil.

Conflict of Interest - Nil.

Funding - Nil. 